\title{
Parameters of bank vole decontamination from radiocesium and radiostrontium
}

\author{
M.D. Bondarkov', S.P. Gaschak', Ju.A. Goryanaya ${ }^{1}$, A.M. Maximenko ${ }^{1}$, A.N. Ryabushkin ${ }^{1}$, \\ O.V. Salyi', A.A. Shulga', S. Awan , R.K. Chesser ${ }^{1,2}$ and B.E. Rodgers ${ }^{1,2}$ \\ ${ }^{1}$ International Radioecology Laboratory, Slavutych Division of Intemational Chornobyl Center, \\ P.B. 151, Slavutych, Kievskaya Oblast 07100, Ukraine \\ ${ }^{2}$ Department of Biological Sciences, Texas Tech University, \\ Lubbock, Texas 79409-3131, U.S.A.
}

\begin{abstract}
Chonobyl Zone to lab and fed by "clesn" food over 2 months. Application of specially designed beta-gamma spectrometer and live counting methods allowed describing whole body decontamination. Initial whole body activity ranged: 22-385 kBq ${ }^{137} \mathrm{Cs}$ and $0.9-7.7 \mathrm{kBq}{ }^{90} \mathrm{~S}$. Less $0.4 \%$ activity was lost by physical decay during the study, the most - by biological excretion way. In the 2000 study $97.4 \%{ }^{137} \mathrm{Cs}$ activity was excreted with half-life period of $1.93 \mathrm{~d}$, and in the 2001 study $-99.3 \%$ and $2.18 \mathrm{~d}$, respectively. $43 \%{ }^{90} \mathrm{Sr}$ activity contents was excreted with half-life of $13.7 \mathrm{~d}$ in the 2000 study and $59 \%$ with $13.1 \mathrm{~d}$ in the $\mathbf{2 0 0 1}$ study, respectively. 'The rest amount of the radionuclides was considered as non-excreted over the study term. At that, ${ }^{90} \mathrm{Sr}$ and ${ }^{137} \mathrm{Cs}$ loss rate of males was highe than females, and. paradoxically, lactating females over suckling period had more slow reduction both radionuclides, than other females. At birh ${ }^{137} \mathrm{Cs}$ content in newborns was $2-10.5 \%$ of their mother activity, and $0.15-1.12 \%$ of mother's ${ }^{90} \mathrm{Sr}$ content. Over the first $4-8$ days of life (the period of exclusive milk consumption), substantial growth of ${ }^{137} \mathrm{Cs}$ activity took place, reaching a maximum value of $30-40 \%$ of their initial activity. The ${ }^{90} \mathrm{Sr}$ activity in nowborns continued to grow over the suckling period, even with the steady decrease of ${ }^{90} \mathrm{~S} r$ activity in mother's body. By the end of the suckling period (15-18 days), total ${ }^{90} \mathrm{Sr}$ activity in a litter increased and attained an average of 34 times their initial value.
\end{abstract}

\section{INTRODUCTION}

The small mammals are very popular objects, which get under intent attention of scientists in case of radiation pollution of environment. And a first that attracts attention is remarkable difference in radioactive contamination of the organisms: both of animals of different species and individuals of one species [1]. Undoubtedly, it must influence on estimation of dose, which the animals receive. Within basic reasons, which determine such differences, there are contamination heterogeneity of the inhabited area, differences of the rations and peculiarities of metabolism of different animals groups. Whilst a much attention is given to investigate the first two factors, the metabolism peculiarities remain out of research frame. As the result, there is not so much information about accumulation and excretion parameters in representatives of wild fauna, therefore to compare it is needed to refer data got for lab mice or rats [2-6]. At the same time, it is evident even on these data that at the half-life of accumulation and excretion of the radionuclides in several days the differences on the similar order of magnitude can significantly reflect on the general contamination level of the animal organism.

Provision of the similar information is possible only in the experiment with long-term keeping of the wild animals at the lab conditions and at the existence of technical opportunity to estimate the radionuclide contents in organism of the alive animals. This study was carried out to achieve this goal. Considering it as a first stage of the investigation of ${ }^{90} \mathrm{Sr}$ and ${ }^{137} \mathrm{Cs}$ metabolism's parameters, the main task of the given stage was to estimate parameters of the radionuclides excretion on the instance of small mammals.

\section{OBJECTS AND METHODS}

As a model object a bank vole (Clethrionomys glareolus) has been selected, 13 individuals were caught in 2000 on one from central plots of the Chornobyl zone (in $5 \mathrm{~km}$ to SWW from destroyed $4^{\text {th }}$ unit) with 
radioactive contamination near $690 \pm 60 \mathrm{Ci} / \mathrm{km}^{2}$ of ${ }^{137} \mathrm{Cs}$ and $350 \pm 20 \mathrm{Ci} / \mathrm{km}^{2}$ of ${ }^{90} \mathrm{Sr}$. In 2001 next fifteen voles were captured for additional study.

Over 2 month the animais were kept at the lab conditions in individual cages. The experimental diet consisted from a concentrate "Zeigler" (small animals' food: for rats, guinea-pig, rabbits) and oat flakes. As a juicy food the voles got apple and cucumber pieces. Daily we changed paper litter, which the voles used also as a nest material. Every 1-5 days all animals were weighted to check their general state.

The estimation of whole body radionuclide contents performed: over first 12 days - daily, and thereafter- once per every 3-12 days. For that the animals were placed into a special pasteboard container $(70 \times 40 \times 40 \mathrm{~mm}$ ) with upper wall from polyethylene membrane (no more $0.1 \mathrm{~mm}$ thick). The container's size allows the animals to be free enough. In order to exclude influence of the possible contamination of the containers on the estimation results, the containers used only once.

To estimate the radionuclides contents at the study of 2000 we used a specially elaborated betagamma spectrometer, having thin-film $(1 \mathrm{~mm})$ scintillator detector, which allows to have in 20 times less registration efficiency of gamma quantum with energy of $661 \mathrm{keV}$ than one of electrons with the same energy. Additionally a special mathematics provision has been elaborated to split the combined spectrum of electrons, gamma-quantum and X-rays on separate contributions of ${ }^{137} \mathrm{Cs}$ and ${ }^{90} \mathrm{Sr}{ }^{90} \mathrm{Y}$. The processing of the experimental spectrum was performed by putting down in it spectrums of mouse phantoms with known contents of ${ }^{137} \mathrm{Cs}$ and ${ }^{90} \mathrm{~S} /{ }^{90} \mathrm{Y}$, which were specially created and counted on the same spectrometer. It allowed simultaneously to register both ${ }^{137} \mathrm{Cs}$ and ${ }^{90} \mathrm{Sr} /{ }^{90} \mathrm{Y}$. the main radionuclides existing in animal organism in the Chomobyl zone. The container with animal was placed into a lead shelter with detector. Counting duration of the each animal varied from 5 to 30 minutes depending on total level of the radioactivity. Radiochemical and gamma-spectrometric determinations of total contents, respectively, ${ }^{90} \mathrm{Sr}$ and ${ }^{137} \mathrm{Cs}$, performed at the end of the study, confirmed reliability of the method.

At the study of 2001 we use a gamma-spectrometer with Ge-Li detector to determine ${ }^{13 T} \mathrm{Cs}$ activity contents in the animal separately and parallel with ${ }^{90} \mathrm{Sr}$ determination on the beta-spectrometer. That allowed to avoid certain influence of large ${ }^{90} \mathrm{Sr}$ contents on determination low ${ }^{137} \mathrm{Cs}$ one on late stages of the study.

We considered a chart of the radionuclide content alteration in the animal body relatively to initial values.

Theoretically physiological state of the animals must reflect on the radionuclide exchange processes. Therefore we compared the animals groups, having most evident physiological differences: 1) females, born babies and fed them by milk during 2-2.5 weeks (lactating female), 2) non born females (nonlactating female) and 3) males.

\section{RESULTS AND DISCUSSION}

Prolonged 50-56-days keeping the bank voles at the lab on the experimental relatively "clean" diet reflected lightly on their general state. It the 2000 study, body mass of the 4 animals remained almost the same and fluctuated in $\pm 5 \%$ limits of the initial value, that one of the rest grew on $10-40 \%$. In the second study the most animals had loss of weight for $10-30 \%$ of initial value over first week, but later they recovered and exceeded it on 10-40\%. Only one animal (female TK 96251 ) died on $19^{\text {th }}$ day of the 2000 study and one female (TK96345) on $10^{\text {th }}$ day of the 2001 study. Interesting, that both had highest initial radionuclide content within the study samples: TK96251 $-7.2 \mathrm{kBq}{ }^{90} \mathrm{Sr}$ and $385 \mathrm{kBq}{ }^{137} \mathrm{Cs}$. TK96345 $1.2 \mathrm{kBq}{ }^{90} \mathrm{Sr}$ and $125 \mathrm{kBq}{ }^{137} \mathrm{Cs}$; in some times more that other animals. In $9^{\text {th }}, 10^{\text {th }}$ and $12^{\text {th }}$ day of the 2000 study females, respectively, TK 96261 , TK 96257 and TK 96251 gave birth babies. In 2001 study females TK 96335 and TK 96344 gave newborns on $3^{\text {rd }}$ and $16^{\text {th }}$ day, respectively.

The results of regular counting of the radionuclide content in bank vole organism showed that since first days of the study total radioactivity of the animal became rapidly decreased (fig. 1). At that, while

${ }^{90} \mathrm{Sr}$ content decreased in average on $44-50 \%$ by the end of the study, the ${ }^{137} \mathrm{Cs}$ one - on $97-99.7 \%$.

Dynamics of the radionuclide excretion, proceeding from nature of that process, can be described by exponential equation of first, second and more order. At the given case, decrease of the both nuclides is described more better by the equation of the first order: 
$C_{t}=C_{0}\left[a_{1}+a_{2} e^{-\frac{0.693}{T_{1}}}\right]$, where

$C_{t}$ - radionuclide content in animal body at $t$ day from the study begin; $C_{\theta}$ - initial content of the radionuclide; $a_{1}$ and $a_{2}$ - respectively, parts of constant and excreting fraction of the radionuclide; $T_{1}-$ effective half-life period of excreting fraction of the radionuclide.

In simplified view, physical sense of that includes in that the radionuclide in the animal tissues is in compound both of excreting and not excreting fraction. At least, over observation period. However, in reality everything occurs much more complicated: the radionuclide can be repeatedly involved in number exchange processes inside organism before it would be excreted out or disintegrate; and "constant" fraction has indefinite large value of half-life period, comparable with animal life duration.

Calculation of the given function's parameters showed that radiocesium excretion in bank vole (Tabl. 1) occurs much more rapid than that known in lab rat $(6.67-7.2 \mathrm{~d}[2,3]): 97-99 \%$ activity is excreted with $\mathrm{T}_{\text {eft }} 1.93-2.18 \mathrm{~d}$. At that, due to more large part of exereted ${ }^{137} \mathrm{Cs}\left(a_{2}\right)$ decontamination of vole's body in the 2001 study was being remarkably more fast than in the previous study (Fig. 1). In the both cases males were decontaminated more intensive than females (Fig. 2), and, in despite of expectation, ${ }^{137} \mathrm{Cs}$ was excreted more slow from organism of the lactating females (over suckling period), than from nonlactating one (Fig. 3). Moreover, non-lactating females are similar to males by ${ }^{{ }_{3}}{ }^{\mathrm{C}} \mathrm{Cs}$ excretion parameters.

The calculated half-life period of the ${ }^{90} \mathrm{Sr}$ excretion was 13.1-13.7d (table 2), that also considerably less that in the lab rat $-233 \mathrm{~d}$ [2]. In contrast to ${ }^{137} \mathrm{Cs}$ trends, only about $43-59 \%$ of ${ }^{90} \mathrm{Sr}$ whole-body activity was being excreted over observations period, whilst the rest remained as a constant immobile fraction (fig. 1). In any case, the last is excreted much more slow, over or comparable vole's lifetime (312 months). As well as that was for ${ }^{137} \mathrm{Cs}$, males were decontanrinated from ${ }^{90} \mathrm{Sr}$ more intersive than females (fig. 4), non-lactating females - than lactating (fig. 5), and trends and parameters of ${ }^{90} \mathrm{Sr}$ loss in males and non-lactating females were rather close.

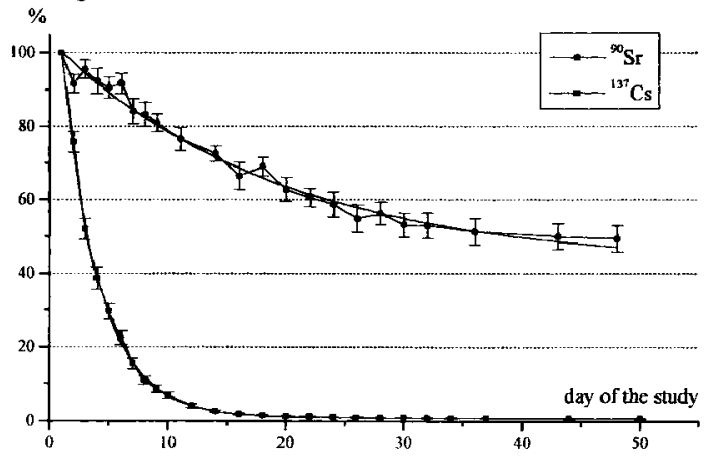

Figure 1: Dynamics of ${ }^{90} \mathrm{Sr}$ and ${ }^{137} \mathrm{Cs}$ content decrease in bank vole organism in 2001 study (chart of 2000 study is similar), \% of initial content

Proceeding from half-life of the radionuclide physical decay $\left(T_{C s}=10981.99 \mathrm{~d}, T_{S r}=10585 \mathrm{~d}\right)$, that is possible to be affirmed that over the all study period no more $0.353 \%$ initial content of ${ }^{137} \mathrm{Cs}$ and $0.366 \%$ ${ }^{50} \mathrm{Sr}$ have disintegrated. Hence, the decrease of the radionuclide content in the vole's body happened due to bio logical excretion (within urine, feces, milk, embryos).

Beginning from the third week of the 2000 experiment and till the its end, total ${ }^{137} \mathrm{Cs}$ content in voles' body was estimated as $2-3 \%$ of initial one, without delineation of any tendency, though the absolute values of the activity were far from detecting limit yet. Since the radionuclide intake with food 
was excluded, the absence of any indication of the subsequent decrease can be explained by some reasons: methodological incompleteness and gradual alteration of ${ }^{90} \mathrm{Sr} /{ }^{137} \mathrm{Cs}$ ratio from $0.01-0.03$ at the beginning up to $0.5-0.6$ and more since $16^{\text {th }}-19^{\text {th }}$ days. Therefore, in the 2001 study we came to use gamma-spectrometer for ${ }^{137} \mathrm{Cs}$ evaluation.

Table 1: Parameters of ${ }^{137} \mathrm{Cs}$ activity reduction in bank vole's body over the study

\begin{tabular}{|c|c|c|c|}
\hline & $a_{1}$ & $a_{2}$ & $T_{1}$ \\
\hline \multicolumn{4}{|c|}{ Study of 2000 year } \\
\hline All fermales & $0.031 \pm 0.003$ & $0.969 \pm 0.014$ & $1.89 \pm 0.04$ \\
\hline Lactating females & $0.033 \pm 0.004$ & $0.967 \pm 0.017$ & $1.89 \pm 0.05$ \\
\hline Non-lactating females & $0.031 \pm 0.003$ & $0.969 \pm 0.015$ & $1.87 \pm 0.04$ \\
\hline Males & $0.023 \pm 0.002$ & $0.977 \pm 0.013$ & $1.95 \pm 0.04$ \\
\hline All animals & $0.026+0.002$ & $0.974 \pm 0.013$ & $1.93 \pm 0.04$ \\
\hline \multicolumn{4}{|c|}{ Study of 2001 year } \\
\hline All fernales & $0.008 \pm 0.001$ & $0.992 \pm 0.006$ & $2.23 \pm 0.02$ \\
\hline Lactating fernales & $0.047 \pm 0.005$ & $0.953 \pm \mathbf{0 . 0 1 8}$ & $2.33 \pm 0.07$ \\
\hline Non-lactating females & $0.008 \pm 0.001$ & $0.992 \pm 0.009$ & $2.17 \pm 0.03$ \\
\hline Males & $0.006 \pm 0.002$ & $0.994 \pm 0.014$ & $2.14 \pm 0.04$ \\
\hline All animals & $0.007 \pm 0.001$ & $0.993 \pm 0.009$ & $2.18 \pm 0.03$ \\
\hline
\end{tabular}

Table 2: Parameters of ${ }^{90}$ Sr activity reduction in bank vole's body over the study

\begin{tabular}{lccc}
\hline & $a_{i}$ & $a_{2}$ & $T_{1}$ \\
\hline Non-lactating females & Study of 2000 year & & \\
Males & $0.62 \pm 0.05$ & $0.38 \pm 0.04$ & $10.8 \pm 3.6$ \\
All animals & $0.52 \pm 0.05$ & $0.48 \pm 0.04$ & $14.0 \pm 3.5$ \\
\hline \multicolumn{1}{l}{ All fernales } & $0.57 \pm 0.05$ & $0.43 \pm 0.04$ & $13.7 \pm 3.9$ \\
\hline Lactating females & Study of 2001 year & & \\
Non-lactating females & $0.41 \pm 0.07$ & $0.59 \pm 0.06$ & $20.3 \pm 4.6$ \\
Males & $0.78 \pm 0.16$ & $0.22 \pm 0.14$ & $11.7 \pm 13.9$ \\
All animals & $0.42 \pm 0.07$ & $0.58 \pm 0.06$ & $15.8 \pm 4.1$ \\
\hline
\end{tabular}

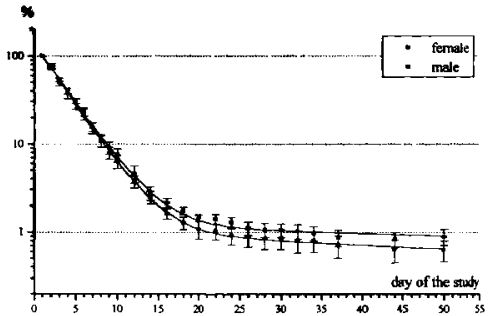

Figure 2: Reduction of ${ }^{137} \mathrm{Cs}$ contents in body of male and female at the 2001 study; $\%$ of initial value (chart of 2000 study the same)

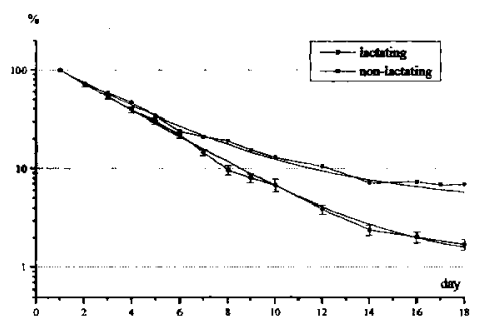

Figure 3: Reduction of ${ }^{137} \mathrm{Cs}$ contents in body of lactating and non-lactating female; \% of initial value; data of lactating female - \% of initial contents in delivery date (by 2001 data)

Radionuclide contents loss by birth of babies was considerable less than daily $10-40 \%$ decrease of the ${ }^{137} \mathrm{Cs}$ activity and $1-2 \%$ decrease of the ${ }^{90} \mathrm{Sr}$ activity.

At birth ${ }^{137} \mathrm{Cs}$ content in bank vole litters was $2-10.5 \%$ of the activity of their mother. Babies born in 2001 attained values of $9-10.5 \%$ of the ${ }^{137} \mathrm{Cs}$ activity of mothers, while in 2000 only $2-6.5 \%$ was reached during the nursing period. The number of babies in a litter did not influence the percentage of ${ }^{137} \mathrm{Cs}$ attained. Furthermore, over the first 4-8 days after birtb (the period of exclusive milk consumption), 
substantial growth of ${ }^{137} \mathrm{Cs}$ activity took place, reaching a maximum value of $30-40 \%$ of their initial activity. Babies from large litters (5-6 individuals) grew slower in first week of life, and ${ }^{137} \mathrm{Cs}$ activity in their bodies began to decrease later than in the small litters ( 3 individuals). Reduction of total ${ }^{137} \mathrm{Cs}$ activity in litters was caused by natural excretion of the radionuclide and by reduced contributions of ${ }^{137} \mathrm{Cs}$ from mothers' milk. In offspring born in 2001 the rate of reduction was remarkably faster than was observed in those born in 2000 .

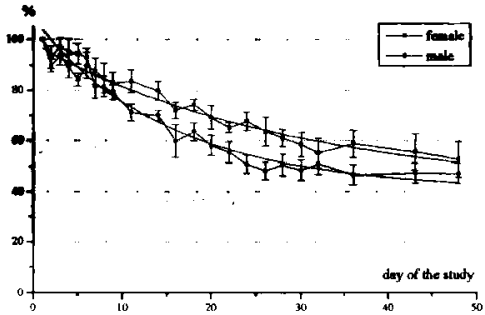

Figure 4: Reduction of ${ }^{90} \mathrm{Sr}$ contents in body of male and female at the 2001 study; \% of initial value (chant of 2000 sudy is similar)

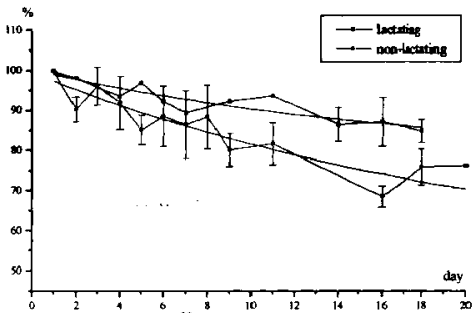

Figare 5: Reduction of ${ }^{90} \mathrm{Sr}$ contents in body of lactating and non-lactating female; $\%$ of initial value; data of lactating female - \% of initial contents in delivery date (by $200 \mathrm{I}$ data)

Litters were bom with $0.15-1.12 \%$ of their mother's ${ }^{90} \mathrm{Sr}$ content (averaged over one week be fore delivery). Furthermore, the ${ }^{\infty} \mathrm{Sr}$ activity in babies continued to grow over the entire suckling period, even with the steady decrease of ${ }^{90} \mathrm{Sr}$ activity in the mother's body. By the end of the suckling period (15-18 days), the total activity of ${ }^{90} \mathrm{Sr}$ in a litter increased and attained an average of 3-4 times their initial value. In one litter, the growth of ${ }^{90} \mathrm{Sr}$ activity was more than 10 times their initial value. The number of babies in a litter did not influence the growth of ${ }^{90} \mathrm{Sr}$ activity. Subsequent to weaning a decrease in total ${ }^{90} \mathrm{Sr}$ activity was observed. This loss is due to natural biological turnover of ${ }^{90} \mathrm{Sr}$ in bone. As in case of ${ }^{137} \mathrm{Cs}$, the rate of reduction of total ${ }^{90} \mathrm{Sr}$ activity in newborns was substantially higher in the 2001 study than in 2000 .

If to assume that the increase of total radioactivity of the offspring during first some days of their life occurred exclusively due to mother milk, and that removing of the radionuclides with excretes from babies organism was negligible, then the daily loss of ${ }^{90} \mathrm{Sr}$ and ${ }^{137} \mathrm{Cs}$ in mother with milk can be estimated. On our calculation, it is $0.35-1.39 \%{ }^{137} \mathrm{Cs}$ and $0.09-0.58 \%{ }^{90} \mathrm{Sr}$ of the content in the mother organism. This is an approximate evaluation and concerning only to the first week after babies birth.

Interpretation of the obtained data, of course, demands more decper analysis basing on physiology and biochemistry of the organism, however, for the now it can be kept in mind as useful information at the analysis of primary empiric data, obtained at the field studies.

\section{SUMMARY}

Comparison of the results, obtained for the bank vole, with the analogical published data for laboratory rats (as that be done in given paper), of course, is not very good, since the voles are in 6-10 times less than rats and, hence, differ from them by substance exchange rate. Essentially, we have got just that: ${ }^{137} \mathrm{Cs}$ is evacuated from the voles' body in 3.4 and ${ }^{90} \mathrm{Sr}$ in 17 times faster. Probably, it should be expected, that in animals as big as bank vole (genius: Microtus, Apodemus, Sylvaemus) the parameters of the radionuclide removing would be similar. However, the difference is not excluded between them, because of differences of biology, nutrition and mobility of those species. According with our experiment results, even the individuals of different sex had considerable differences of these parameters. 
In the results of the our investigation, it has been found out that "decontamination" of the voles" organism from radioactive isotopes ${ }^{90} \mathrm{Sr}$ and ${ }^{137} \mathrm{Cs}$ is fulfilled, mainly, through the biological excretion, at that, in females more important role belongs to combined removing with urine and feces, while in male just only by this way.

The fast removing of ${ }^{137} \mathrm{Cs}$ supposes the same fast accumulation of it. Thus, at the natural conditions, over the lifetime (3-12 months), the contamination level of the vole organism can repeatedly change depending on food, at that, the fluctuation amplitudes can have 10 -fold and more values. In that time, total content of ${ }^{90} \mathrm{Sr}$, most likely, will not have so acute fluctuations, and in case of its constant intake with food, most likely, will increase steadily.

The study method used of alive counting of ${ }^{90} \mathrm{Sr}$ and ${ }^{137} \mathrm{Cs}$ content gives a great opportunity to investigate dynamics of their accumulation and excretion in organism of small mammals. It is remarked by efficiency, simplicity of performance, stores the animal life. Nevertheless, the certain restrictions, discussed above, demands application of individual approaches at the investigations of different species of animals and at the different radionuclides ratios in their organism. Especially, to estimate absolute values of the activity content. However, in order to estimate relative values this method is very handly and effective already now.

\section{References}

[1] Chesser R.K., Sugg D.W., Lomakin M.D., Van Den Bussche R.A., DeWoody J.A., Jagoe C.H., Dallas C.E., Whicker F.W., Smith M.H., Gaschak S.P., Chizhevsky I.V., Lyabick V.V., Buntova E.G., Holloman K., Baker R.J. Concentrations and dose rate estimates of ${ }^{134,137} \mathrm{Cs}$ and ${ }^{90} \mathrm{Sr}$ in small mammals at Chomobyl, Ukraine // Environmental Toxicology and Chemistry. - 2000. - Vol. 19, No. 2. - pp. 305-312

[2] ICRP. 1959. Permissible dose for internal radiation. Health Physics. 3:1

[3] Moiseyenko M.I. et al. Dynamics of dose burden on organs and tissues of animals at prolonged intake of ${ }^{137} \mathrm{Cs},{ }^{90} \mathrm{Sr}+{ }^{90} \mathrm{Y}$ to organism // In: "Problems of the Chornobyl exclusion zone". - Kyiv.: Naukova Dumka, 1998. - Iss. 5. - pp. 167-173, (in Ukrainian)

[4] Kitchings T., DiGregorio D., Van Voris P. 1976. A review of the ecological parameters of radionuclide turnover in vertebrate food chains. In Cushings CE et al., eds, Radioecology and Energy Resources. Dowden Hutchinson and Ross, Stroudsburg, PA.

[5] Reichle D.E., Dunaway P.B., Nelson D.J. 1970. Turnover and concentration of radionuclides in food chains. Nuclear Safety. 11:43.

[6] Buldakov L.A., Yerokhin R.A. Content of strontium-90 in organism of rats at chronic perioral intake // Distribution, biological action and excretion acceleration of radioactive isotopes. - Moscow:

Medicina, 1964. - pp. 98-105. (In Russian) 